\title{
Post-traumatic epilepsy: current and emerging treatment options
}

\author{
This article was published in the following Dove Press journal: \\ Neuropsychiatric Disease and Treatment \\ II August 2014 \\ Number of times this article has been viewed
}

\author{
Jerzy P Szaflarski ${ }^{1,3}$ \\ Yara Nazzal ${ }^{1,3}$ \\ Laura E Dreer ${ }^{2}$ \\ 'Department of Neurology, \\ ${ }^{2}$ Department of Ophthalmology, ${ }^{3} \mathrm{UAB}$ \\ Epilepsy Center, University of Alabama \\ at Birmingham, Birmingham, AL, USA
}

Abstract: Traumatic brain injury (TBI) leads to many undesired problems and complications, including immediate and long-term seizures/epilepsy, changes in mood, behavioral, and personality problems, cognitive and motor deficits, movement disorders, and sleep problems. Clinicians involved in the treatment of patients with acute TBI need to be aware of a number of issues, including the incidence and prevalence of early seizures and post-traumatic epilepsy (PTE), comorbidities associated with seizures and anticonvulsant therapies, and factors that can contribute to their emergence. While strong scientific evidence for early seizure prevention in TBI is available for phenytoin (PHT), other antiepileptic medications, eg, levetiracetam (LEV), are also being utilized in clinical settings. The use of PHT has its drawbacks, including cognitive side effects and effects on function recovery. Rates of recovery after TBI are expected to plateau after a certain period of time. Nevertheless, some patients continue to improve while others deteriorate without any clear contributing factors. Thus, one must ask, 'Are there any actions that can be taken to decrease the chance of post-traumatic seizures and epilepsy while minimizing potential short- and long-term effects of anticonvulsants?' While the answer is 'probably,' more evidence is needed to replace PHT with LEV on a permanent basis. Some have proposed studies to address this issue, while others look toward different options, including other anticonvulsants (eg, perampanel or other AMPA antagonists), or less established treatments (eg, ketamine). In this review, we focus on a comparison of the use of PHT versus LEV in the acute TBI setting and summarize the clinical aspects of seizure prevention in humans with appropriate, but general, references to the animal literature.

Keywords: traumatic brain injury, TBI, seizures, epilepsy, seizure prevention, cognition, EEG, antiepileptic drugs

\section{Introduction}

In about $6 \%$ of patients with epilepsy, seizures are thought to be the result of previous head trauma; frequently, seizures in these patients are difficult to control with standard antiepileptic drugs (AEDs). ${ }^{1}$ The presence of early and late seizures has significant effect on subsequent outcomes, including medication use, quality of life, employment, and psychosocial adjustment. In these patients, the original insult is frequently identified from the history, but the severity of the injury may be difficult to judge. Based on studies conducted over the last several decades, patients who have suffered moderate or severe traumatic brain injury (TBI) are typically placed on an AED right after the initial trauma, usually phenytoin (PHT), but more recently also on levetiracetam (LEV), in order to alter the progression of epileptogenesis to late seizures and epilepsy. If seizures are not present in the first 7 days after trauma, the AED is weaned, with an expectation that seizures will not occur in the future. Since the concept of seizure and epilepsy prevention after TBI is well established, it is incumbent upon us to determine
Correspondence: Jerzy P Szaflarski UAB Epilepsy Center, University of Alabama at Birmingham, 312 Civitan International Research Center, 1719 6th Avenue South, Birmingham, AL 35294-002I, USA

Emailszaflaj@uab.edu
Neuropsychiatric Disease and Treatment 20|4:10 |469-1477 
not only which factors, when present or absent in the latent period (time between trauma and late seizures), are important for initiating and completing the cascade of events that eventually lead to seizure occurrence, but also how we can modulate or abort this process so that seizures never occur. It is imperative to develop strategies that change the process of epileptogenesis while concurrently decreasing the chance of the development of unwanted comorbidities (eg, worsening of cognitive deficits related to TBI and AEDs). Finally, it is important to be mindful of the financial implications - PHT was found to be more cost effective than LEV in a setting of seizure prevention after TBI, but this gap may be disappearing with the costs becoming similar in the recent years, and this calculation did not take into account the effects of these treatments on long-term costs. ${ }^{2}$

In this review focusing on the comparison between PHT and LEV, we summarize the clinical aspects of seizure prevention in humans, with appropriate but general references to animal literature, and provide brief discussion of potential new developments.

\section{Epidemiology of early vs late post-traumatic epilepsy}

The epidemiology of post-traumatic epilepsy (PTE) is well established. Early seizures are defined as seizures occurring in the first 7 days of trauma, while PTE is defined as seizures occurring after this period. ${ }^{3}$ The incidence of early seizures after TBI is reported to be between $2.6 \%$ and $16.3 \%$, with the differences being dependent mainly on study design. ${ }^{3,4}$ At least in univariate analysis, the presence of early seizures predisposes the development of late PTE; overall early seizures are thought of as an epiphenomenon and a result of an acute injury, with their presence not necessarily equating with the development of late PTE. ${ }^{3,4}$ In fact, the pathophysiologic mechanisms leading to early post-traumatic seizures are not clearly understood, and multiple factors are thought to play a role, including interruption of the blood-brain barrier, presence of hemorrhage, and injury-related excitotoxicity. ${ }^{5-8}$

The reported incidence of late PTE is dependent, in part, on the study design. In a population-based cohort of 2,747 patients with TBI, the risk of PTE after a severe TBI was $7.1 \%$ at 1 year and $11.5 \%$ at 5 years. After moderate brain injury, the risk of PTE was $0.7 \%$ at 1 year and $1.6 \%$ at 5 years. The risk of PTE was not increased after mild head injury defined as head injury without skull fracture with either loss of consciousness or posttraumatic amnesia lasting less than 30 minutes. $^{9}$ In the trial of PHT versus placebo for seizure prevention after TBI, $86 \%$ of patients who developed seizures did so within 2 years of the incident trauma. ${ }^{10,11}$ Finally, in a large population-based study, the risk of PTE was relatively small and non-significantly elevated after mild injury (1.5 after adjusting for all other factors) and increased after moderate (2.9 times) and severe (17.0 times) TBI. ${ }^{3}$ Salazar et $\mathrm{l}^{12}$ reported the overall occurrence of PTE in 53\% of Vietnam veterans who had suffered from various penetrating head wounds and who required neurosurgical intervention. More than $90 \%$ of PTE presented within the first 10 years of trauma; occurrence of PTE significantly correlated with multiple risk factors, including brain volume loss, the presence of metal fragment, hematoma, and residual neurological deficits. ${ }^{12}$ These authors estimated the risk of developing epilepsy within the first year of penetrating head trauma to be 580 times higher than in a population not at risk. Finally, a recent cross-sectional study investigated PTE in a cohort of the veterans of the Afghanistan and Iraq conflicts to show age-adjusted prevalence of 6.1 per 1,000 , with odds of developing epilepsy related to previous TBI of 18.77 (95\% confidence interval [CI] 9.21-38.23) when compared with veterans who did not suffer TBI. ${ }^{13}$ Thus, the picture painted by these epidemiological studies is that the more severe the injury the more likely the person with TBI is to develop PTE; that more than $80 \%$ of PTE starts within 2 years of TBI; that presence of skull fracture, penetrating injury, and neurological deficits predispose to the development of PTE; and that age at the time of injury may be a factor in the development of PTE.

\section{Seizure and epilepsy prevention after TBI}

The idea behind the use of AEDs in the immediate post-injury period is based on the desire to prevent the development of late PTE as a long-term, and at times debilitating, comorbidity, ie, finding a time window for an intervention that will stop the process of epileptogenesis. ${ }^{7}$ However, it needs to be recognized that besides seizures and PTE, TBI is frequently followed by various immediate and long-term deficits. ${ }^{7,14,15}$ These include, among others, focal neurological deficits, cognitive problems, changes in mood (eg, depression), movement disorders, sleep disorders, and behavioral problems. Some of these deficits may improve or resolve relatively quickly after the injury while some of them may worsen after initial improvement. ${ }^{16,17}$ Further, information on how treatment with AEDs in the acute phase influences long-term outcomes, including the development of PTE, is relatively sparse. Prophylaxis against seizures is a part of standard therapy in the acute phase of moderate or severe TBI. As per guidelines from multiple organizations, including the Brain Trauma 
Foundation and the American Academy of Neurology, the most commonly used prophylactic agent is PHT, which is typically administered for the first 7 days after TBI. ${ }^{18,19}$ But, while prophylaxis with PHT decreases the incidence of early posttraumatic seizures from $14.2 \%$ to $3.6 \%$ when compared with placebo, this treatment has not been shown to decrease the risk of late posttraumatic seizures and epilepsy. ${ }^{1,11}$

PHT has numerous side effects and drug interactions and exhibits complex nonlinear pharmacokinetics that necessitate therapeutic drug monitoring; its steady state concentrations are often not achievable within the first 7 days of therapy. Further, maintaining therapeutic levels of PHT is challenging in patients with TBI because the levels are affected by multiple factors frequently present in TBI patients, including decreased protein binding, variable gastrointestinal absorption, and increased drug clearance. ${ }^{20}$ Further, while PHT reduces seizures, concerns have been raised that it may also adversely affect cognitive recovery, at least in some forms of brain injury. A recent study investigated the outcomes of patients treated with PHT for seizure prophylaxis after TBI compared with matched patients who, based on clinical judgment, had not received PHT prophylaxis. ${ }^{20}$ While no differences were observed in the incidence of seizures between groups, patients treated with PHT showed worse outcomes, including Glasgow Outcomes Scale and modified Ranking Scale (both $P<0.05$ ). Multiple caveats to this study need to be considered, including small sample size, lack of randomization, and the choice of treatment versus no treatment based on personal preferences of the providers rather than predetermined schemes. ${ }^{20}$

An alternative to PHT may be LEV, an agent recently added to the seizure-prevention armamentarium..$^{21-25}$ The availability of this AED is especially relevant for critically ill patients with TBI because of the ease of administration, low rate of adverse events, and potential for improved outcomes. ${ }^{19,20,24}$ A recently reported small-scale, singleblinded randomized trial suggests the use of LEV rather than PHT in acute TBI may be associated with better 6-month cognitive outcomes. ${ }^{24,26}$ While promising, these preliminary single-blinded data are not sufficient to warrant a change in clinical practice. More studies are needed to determine its long-term impact after injury. To date, no prospective, double-blind randomized controlled trials (RCTs) have been conducted to compare the effects of LEV versus PHT on neurocognitive and seizure outcomes among individuals with moderate or severe TBI. ${ }^{27,28}$

Several 'older' AEDs have been evaluated for the treatment of early post-traumatic seizures with a goal of targeting the development of late PTE. These include PHT, valproate (VPA), and carbamazepine (CBZ). ${ }^{18,24}$ The available data on PHT, VPA, and CBZ were reviewed in a recent 'practice parameter' and are discussed here only briefly. ${ }^{18}$ For PHT, evidence from pooled studies indicates a significantly lower risk of early post-traumatic seizures in patients who receive PHT for seizure prophylaxis when compared with placebo (relative risk 0.37) and no reduction in late post-traumatic seizures (relative risk 1.05). Oral (via feeding tube) CBZ, given immediately after TBI and continued for 18-24 months, was used for seizure prophylaxis in one quasi-randomized study in which outcomes were compared with a placebo group. ${ }^{29}$ Patients treated with CBZ showed a significantly lower probability of early and late post-traumatic seizures, but the results of this study are confounded by the fact that patients were treated initially with intravenous PHT until they were able to receive oral CBZ. Finally, one study evaluated VPA for seizure prevention after TBI to show similar incidences of seizures in patients randomized to 1 week of PHT, 1 month of VPA, or 6 months of VPA $(P=0.19)$ and a trend toward higher mortality with VPA $(P=0.07)$; the effects of both AEDs on neuropsychological health were similar. ${ }^{30,31}$ Based on these results the use of VPA for seizure prevention cannot be recommended. Overall, this is surprising because VPA has been shown to be neuroprotective in several models of acute central nervous system injury (for review, see Chen et $\mathrm{al}^{32}$ ). Thus, the available studies provide level 1 evidence for the short-term use of PHT for seizure prevention in the setting of acute brain injury, while the use of VPA and CBZ in this setting is questionable. Currently, there is no class I evidence that the 'older' AEDs should be used for long-term prevention of PTE. ${ }^{18}$

The results of the previous studies put into perspective the proposed use of LEV in the setting of acute TBI. In animal studies, LEV has been shown to have several mechanisms of action, including modulation of neuropeptide $\mathrm{Y}$ receptors and neuronal $\mathrm{Ca}^{++}$channels, threshold elevation for L-type $\mathrm{Ca}^{++}$channel neuronal currents, modulation of neurotransmitter release via binding to the synaptic vesicle protein 2A (inhibition of $\mathrm{Ca}^{++}$release from intracellular stores), and opposition of the negative modulation of gammaaminobutyric acid (GABA)- and glycine-gated currents. ${ }^{21,33}$ These mechanisms of action could explain the unique antiepileptogenic activity of LEV, including neuroprotection, seizure prevention, and improved cognitive outcomes of LEV use in animal models of brain injury, and support its use for seizure prevention in moderate and severe TBI. To offer more detail, LEV has recently been shown to be 
neuroprotective in a rodent model of controlled cortical impact (CCI) and subarachnoid hemorrhage (effect that has not been observed with PHT); administration of LEV but not PHT improved functional outcomes. ${ }^{34}$ Another rodent study showed that 20 days of LEV treatment following CCI, when compared with placebo, promoted neuronal sparing, decreased the volume of injury, and reduced release of proinflammatory interleukin (IL)-1 $\beta .{ }^{35}$ Finally, LEV alone or in combination with diazepam decreased seizure-related hippocampal neurodegeneration. ${ }^{36} \mathrm{Next}$ is the issue of seizure prevention - the process of epileptogenesis (transformation of normal brain tissue into one capable of spontaneously generating seizures) can be prevented or aborted by LEV. ${ }^{37}$ While it is recognized that LEV is not antiepileptogenic in all animal models, recent studies have shown that LEV aborts hyperexcitability in hippocampal neurons after status epilepticus, ${ }^{38}$ and that it exerts antiepileptogenic effects in spontaneously epileptic rats. ${ }^{39,40}$ Relevant to the discussion is the effect of LEV on cognition - rodents administered LEV beginning 1 day after CCI for 20 days showed improved motor and cognitive functions, including balance (beam walking), spatial learning and memory (maze navigation), and exploration. ${ }^{35}$

In the setting of TBI, some of the issues related to the use of AEDs revolve around the potential effects of these medications on EEG. This is because a growing body of evidence supports the notion that interictal epileptiform discharges (IEDs) and/or seizures result in long-term cognitive deficits. In fact, IEDs have been shown not only to affect cognitive performance, including alertness and speed of processing, at the moment of their occurrence ${ }^{41,42}$ but also to contribute to negative long-term cognitive outcomes such as decreased educational achievement. ${ }^{41-43}$ The negative effect of IEDs on cognition may be comparable to the effects of brief seizures. ${ }^{42}$ There is also evidence that AEDs such as LEV may positively affect the EEG by suppressing IEDs ${ }^{44,45}$ and by improving the overall background of the EEG; these effects are not observed with PHT. ${ }^{46}$ In addition to IEDs, the other common EEG abnormalities observed in TBI are seizures..$^{12,47,48}$ Because of the abundance of EEG abnormalities, it can be difficult to separate the short- and long-term effects of the injury alone from the associated seizures. Animal studies indicate that brain trauma causes global, in addition to focal, abnormalities, and that these abnormalities are most pronounced in the most vulnerable areas - ie, hippocampus. ${ }^{49}$ Further, animal model research has documented the relationship between TBI and seizures ${ }^{50-52}$ and the positive impact of seizure medication treatments on improving neurobehavioral outcomes in
TBI. ${ }^{35,53}$ Recently, human studies have shown that seizures in patients with TBI disproportionately contribute to hippocampal atrophy ${ }^{54}$ that seizures cause increases in intracranial pressure and increased lactate/pyruvate ratio, both of which have deleterious effects on post-TBI recovery, ${ }^{55,56}$ and that patients with seizures related to any type of brain injury, when compared with matched patients without injury, have poorer outcomes and higher mortality. ${ }^{57-60}$ Thus, there is little doubt that seizures and/or IEDs have a negative influence on recovery after TBI.

The next issue that requires consideration is cognitive performance. It is well recognized that most AEDs have negative effects on cognition. The archetypical AED for these effects is topiramate, which has been shown to negatively affect cognitive performance in healthy subjects ${ }^{61-64}$ and in patients with epilepsy ${ }^{65-68}$ The effects of PHT and LEV on cognition are not as pronounced and are likely different. . $4,25,69-74^{-1}$ PHT has been noted to have significant long-term effects on cognition, ${ }^{69}$ including negative effects on concentration, memory, visuo-motor functions and mental speed; these effects may be dose related. ${ }^{75-77}$ Some studies have shown detrimental effects of PHT on cognitive performance when compared with other AEDs (eg, carbamazepine ${ }^{75,77,78}$ ), with these negative effects improving after PHT discontinuation. ${ }^{79}$ On the other hand, LEV as a member of the pyrrolidine class of drugs, may improve cognition via enhancing higher integrative mechanisms of the brain. ${ }^{80,81}$ In fact, LEV has been shown to improve a range of cognitive abilities, including visual short-term memory, ${ }^{82}$ working memory, ${ }^{83}$ motor functions, ${ }^{83}$ psychomotor speed and concentration, ${ }^{72,84}$ and fluid intelligence.$^{85}$ Comparative data are scarce - while one small comparative study showed no difference in cognitive outcomes in patients with epilepsy treated with LEV versus PHT, the authors recognized the lack of power to detect such a difference $(n=10$; participants taking concurrently various AEDs including PHT, CBZ, and/or VPA). ${ }^{86}$ To date, systematic direct comparisons in patients with epilepsy have not been performed, but some studies have indicated improvements in cognition when patients were either transitioned to or treated with LEV monotherapy. ${ }^{44,46}$ Similar improvements in cognitive performance of patients with epilepsy while treated with PHT have not been observed or reported. Finally, individuals with existing cognitive weaknesses (as in TBI) may benefit most from LEV and, in fact, a blinded study showed that recent memory improved most in patients with poor baseline scores. ${ }^{87}$ In contrast to the relative paucity of epilepsy data, a recent study of patients with brain tumors after resection showed that the neurocognitive 
performance of patients treated with LEV was equal to or better than that of matched patients not treated with any AEDs and better than the performance of patients treated with PHT or VPA; in contrast to treatment with PHT, treatments with LEV or VPA were not associated with additional cognitive deficits ${ }^{88}$ Another study in an animal model of Alzheimer's disease showed that treatment with LEV improved cognitive performance via reduction of epileptiform discharges and reversal of hippocampal remodeling, behavioral abnormalities, synaptic dysfunction, and deficits in learning and memory. ${ }^{89}$ In addition to the effects described above, negative effects on EEG and cognitive performance have been observed in patients treated with PHT, especially at high doses and levels. ${ }^{90,91}$

Based on a single RCT, PHT has been shown to have a negative effect on cognitive outcomes in patients with TBI. ${ }^{69}$ A recent study in subarachnoid hemorrhage showed that these effects may be dependent on the dose and treatment duration with $\mathrm{PHT}^{73}$ These findings have led some to question the use of PHT in the setting of TBI. ${ }^{92}$ Newer AEDs, specifically $\mathrm{LEV}$, may be better tolerated and have less adverse impact on the plasticity of recovery. Studies have shown that patients with various etiologies of brain injury, including TBI, experience better outcomes on a variety of measures (adverse effects, Modified Rankin Scale, Glasgow Outcomes Scale) when treated with LEV compared with PHT. ${ }^{24,25,93,94}$ To that end, one small retrospective non-randomized study in TBI evaluated cognitive performance and showed a trend toward improved outcomes among patients treated with LEV versus PHT $(P=0.08) .{ }^{25}$ Finally, a single-blinded RCT has shown better Glasgow Outcome Scale and modified Rankin Scale outcomes in patients with moderate or severe TBI who were treated with LEV versus PHT. ${ }^{24}$

\section{Evidence for seizures after brain injury and the effects of PHT vs LEV}

The likelihood of early seizures is related to the severity of brain injury. ${ }^{14}$ Further, as indicated above, there is some evidence that early seizures may translate into the development of long-term epilepsy, ${ }^{95,96}$ though the data from population-based studies are not entirely in support of this notion. ${ }^{3,9}$ The factors that lead to the establishment of the long-term epileptic state are not fully understood, but there is considerable evidence to suggest that seizures in the acute period may drive changes that will result in the development of PTE. Early use of AEDs may prevent these changes from occurring, reverse the process of early epileptogenesis related to injury, and prevent chronic epilepsy. ${ }^{38,97,98}$
As mentioned previously, because of the short-term risk of seizures and long-term risks of epilepsy, patients with TBI are typically treated with AEDs for 7 days. ${ }^{99-101}$ The most frequently used AED in this setting is PHT. ${ }^{1,11,18}$ However, PHT was also found to be associated with substantial liver toxicity, hypotension, hematologic abnormalities, drug interactions, and sedation, all of which are problematic in critically ill patients. ${ }^{24,94}$ Finally, as indicated above, studies suggest that the use of PHT in this setting is associated with adverse cognitive effects, negative effects on post-TBI recovery, ${ }^{24,25,69}$ and even negative effects on brain anatomy. ${ }^{102}$

The incidence of acute post-TBI seizures depends on whether seizures are reported based on clinical $(\sim 2 \%)$ or continuous EEG (cEEG) ( 22\%) criteria. ${ }^{24,26,59,60,103}$ Recently, cEEG monitoring has been used to determine the incidence of early seizures in critically ill patients. In TBI studies that included cEEG, the incidence of early seizures was found to range from $16 \%$ to $22 \%$, with the vast majority of seizures being non-convulsive (52\%-100\%); approximately $95 \%$ of the identified seizures occurred within 72 hours of trauma. Further, it has been shown that the use of cEEG leads to treatment changes in more than $50 \%$ of the monitored patients. ${ }^{104}$ These findings support the empiric use of AEDs and of the cEEG in the critical care setting. ${ }^{60,105-107}$ Finally, data from a recent randomized and blinded study support the notion that cEEG performed in the first 72 hours after TBI contributes to outcome prediction, ${ }^{26}$ with alpha variability being the most important predictive factor. ${ }^{108}$ Thus, suppressing or eliminating IEDs and seizures should result in improved cognitive performance, while knowledge of the cEEG characteristics can contribute to the overall long-term prediction of outcomes.

Patients with moderate or severe TBI admitted to neuroscience intensive care units are at increased risk for seizures due to their underlying neurological injury. ${ }^{3,9}$ Early-onset seizures in patients with TBI greatly increase the incidence of subsequent seizures/epilepsy and the chance of secondary harm, including increased intracranial pressure, hypoxia, physical injury, and mortality. ${ }^{58,96,99}$ Any of these complications may adversely affect the cognitive and neurological status of patients with TBI, and worsen their clinical outcomes. Further, the presence of seizures or status epilepticus in patients with TBI, similar to other acute neurological insults such as stroke, is associated with increased mortality. ${ }^{58,60}$ Thus, seizure prevention is critical for the long-term outcomes of patients with brain injury, and cEEG may be a valuable biomarker of initial epileptogenicity and for long-term outcomes. 
Thus, to summarize, while there is no level 1 evidence that LEV may be equivalent to or better than PHT when used for seizure prevention in patients with TBI, there is a substantial body of evidence that the use of LEV should be considered in this setting, and further investigations are needed. Finally, prophylaxis of late PTE is neither indicated nor recommended. The data from observational studies and RCTs provide no evidence to support such use of AEDs.

\section{Future directions}

Clinical post-TBI recovery occurs over periods of months and years, and so does the process of epileptogenesis. In fact, epileptogenesis may progress in spite of clinical improvements and in parallel with them. So, the goal of seizure prevention (clinical and research) should be to abort the process of epileptogenesis in addition to short-term seizure prevention, while not negatively affecting the process of post-TBI recovery. Multiple possible avenues need to be further investigated.

At least theoretical grounds exist for the use of several existing and potential AEDs for seizure and PTE prevention in TBI. The possibilities include the use of anticonvulsants that exert activity against AMPA receptors, including lamotrigine and topiramate. ${ }^{109-112}$ In fact, in models of acute brain injury other than TBI, topiramate in the setting of therapeutic hypothermia has already been shown to be neuroprotective. ${ }^{113}$ Further, talampanel and perampanel, two novel AEDs that are known AMPA antagonists, have also been shown to be antiepileptogenic; talampanel is also known to be neuroprotective. ${ }^{12}$ Since another AMPA-receptor antagonist, NS1209, with a mechanism of action similar to that of perampanel (also a selective AMPA-receptor antagonist that decreases hyperexcitability by targeting glutamate activity at post-synaptic AMPA receptors ${ }^{110}$ ) has already been shown to be neuroprotective and effective in various animal models of epilepsy, including status epilepticus, we can probably assume all AEDs with this mechanism of action have similar properties. ${ }^{112}$ Other potential developments may include lacosamide because of its relative ease of use and the availability of intravenous and oral forms that are easily exchangeable, and the fact that this AED has been shown to be potentially anti-epileptogenic in animal models of kindling. ${ }^{114}$ Finally, ketamine, a N-methyl D-aspartate (NMDA) receptor antagonist, has recently gained attention as a possible treatment of refractory status epilepticus; this drug is known to decrease or prevent NMDA-receptor up-regulation and thus decrease the possibility of neurotoxicity via glutamate cascade. ${ }^{115}$ This is especially important in view of a recent study that used CCI as a model of TBI to show that cortical excitability and glutamatergic signaling were altered following injury. ${ }^{5}$ The results of this study suggest that specific cortical neuronal microcircuits may initiate and facilitate the spread of epileptiform activity following TBI and increased glutamatergic signaling due to loss of GABAergic control, which may provide a mechanism by which TBI can give rise to PTE.

\section{Disclosure}

The authors report no conflicts of interest in this work.

\section{References}

1. Temkin NR. Preventing and treating posttraumatic seizures: the human experience. Epilepsia. 2009;50 Suppl 2:10-13.

2. Cotton BA, Kao LS, Kozar R, Holcomb JB. Cost-utility analysis of levetiracetam and phenytoin for posttraumatic seizure prophylaxis. J Trauma. 2011;71(2):375-379.

3. Annegers JF, Hauser WA, Coan SP, Rocca WA. A populationbased study of seizures after traumatic brain injuries. $N$ Engl J Med. 1998;338(1):20-24.

4. Asikainen I, Kaste M, Sarna S. Early and late posttraumatic seizures in traumatic brain injury rehabilitation patients: brain injury factors causing late seizures and influence of seizures on long-term outcome. Epilepsia. 1999;40(5):584-589.

5. Cantu D, Walker K, Andresen L, et al. Traumatic brain injury increases cortical glutamate network activity by compromising GABAergic control. Cereb Cortex. Epub 2014 Mar 7.

6. Herman ST. Epilepsy after brain insult: targeting epileptogenesis. Neurology. 2002;59(9 Suppl 5):S21-S26.

7. Pitkänen A, Kemppainen S, Ndode-Ekane XE, et al. Posttraumatic epilepsy - disease or comorbidity? Epilepsy Behav. Epub 2014 Feb 11.

8. Silverstein FS, Barks JD, Hagan P, Liu XH, Ivacko J, Szaflarski J. Cytokines and perinatal brain injury. Neurochem Int. 1997;30(4-5):375-383.

9. Annegers JF, Grabow JD, Groover RV, Laws ER Jr, Elveback LR, Kurland LT. Seizures after head trauma: a population study. Neurology. 1980;30(7 Pt 1):683-689.

10. Haltiner AM, Temkin NR, Dikmen SS. Risk of seizure recurrence after the first late posttraumatic seizure. Arch Phys Med Rehabil. 1997;78(8):835-840.

11. Temkin NR, Dikmen SS, Wilensky AJ, Keihm J, Chabal S, Winn HR. A randomized, double-blind study of phenytoin for the prevention of post-traumatic seizures. N Engl J Med. 1990;323(8):497-502.

12. Salazar AM, Jabbari B, Vance SC, Grafman J, Amin D, Dillon JD. Epilepsy after penetrating head injury. I. Clinical correlates: a report of the Vietnam Head Injury Study. Neurology. 1985;35(10): $1406-1414$.

13. Pugh MJ, Orman JA, Jaramillo CA, et al. The prevalence of epilepsy and association with traumatic brain injury in veterans of the Afghanistan and Iraq wars. J Head Trauma Rehabil. Epub 2014 Apr 1.

14. Lowenstein DH. Epilepsy after head injury: an overview. Epilepsia. 2009;50 Suppl 2:4-9.

15. Wang HC, Chang WN, Chang HW, et al. Factors predictive of outcome in posttraumatic seizures. J Trauma. 2008;64(4):883-888.

16. Katz DI, Alexander MP, Klein RB. Recovery of arm function in patients with paresis after traumatic brain injury. Arch Phys Med Rehabil. 1998;79(5):488-493.

17. Till C, Colella B, Verwegen J, Green RE. Postrecovery cognitive decline in adults with traumatic brain injury. Arch Phys Med Rehabil. 2008;89(12 Suppl):S25-S34. 
18. Chang BS, Lowenstein DH; Quality Standards Subcommittee of the American Academy of Neurology. Practice parameter: antiepileptic drug prophylaxis in severe traumatic brain injury: report of the Quality Standards Subcommittee of the American Academy of Neurology. Neurology. 2003;60(1):10-16.

19. Rowe AS, Goodwin H, Brophy GM, et al; Neurocritical Care Society Pharmacy Section. Seizure prophylaxis in neurocritical care: a review of evidence-based support. Pharmacotherapy. 2014;34(4): 396-409.

20. Bhullar IS, Johnson D, Paul JP, Kerwin AJ, Tepas JJ 3rd, Frykberg ER. More harm than good: antiseizure prophylaxis after traumatic brain injury does not decrease seizure rates but may inhibit functional recovery. J Trauma Acute Care Surg. 2014;76(1):54-60; discussion 60-61.

21. Dewolfe JL, Szaflarski JP. Levetiracetam use in the critical care setting. Front Neurol. 2013;4:121.

22. Jones KE, Puccio AM, Harshman KJ, et al. Levetiracetam versus phenytoin for seizure prophylaxis in severe traumatic brain injury. Neurosurg Focus. 2008;25(4):E3.

23. Milligan TA, Hurwitz S, Bromfield EB. Efficacy and tolerability of levetiracetam versus phenytoin after supratentorial neurosurgery. Neurology. 2008;71(9):665-669.

24. Szaflarski JP, Sangha KS, Lindsell CJ, Shutter LA. Prospective, randomized, single-blinded comparative trial of intravenous levetiracetam versus phenytoin for seizure prophylaxis. Neurocrit Care 2010;12(2):165-172.

25. Taylor S, Heinrichs RJ, Janzen JM, Ehtisham A. Levetiracetam is associated with improved cognitive outcome for patients with intracranial hemorrhage. Neurocrit Care. 2011;15(1):80-84.

26. Steinbaugh LA, Lindsell CJ, Shutter LA, Szaflarski JP. Initial EEG predicts outcomes in a trial of levetiracetam vs fosphenytoin for seizure prevention. Epilepsy Behav. 2012;23(3):280-284.

27. Benge JF, Phenis RA, Bernett A, Cruz-Laureano D, Kirmani BF. Neurobehavioral effects of levetiracetam in patients with traumatic brain injury. Front Neurol. 2013;4:195.

28. Kirmani BF, Mungall D, Ling G. Role of intravenous levetiracetam in seizure prophylaxis of severe traumatic brain injury patients. Front Neurol. 2013;4:170.

29. Glötzner FL, Haubitz I, Miltner F, Kapp G, Pflughaupt KW. [Seizure prevention using carbamazepine following severe brain injuries]. Neurochirurgia (Stuttg). 1983;26(3):66-79. German [with English abstract].

30. Dikmen SS, Machamer JE, Winn HR, Anderson GD, Temkin NR. Neuropsychological effects of valproate in traumatic brain injury: a randomized trial. Neurology. 2000;54(4):895-902.

31. Temkin NR, Dikmen SS, Anderson GD, et al. Valproate therapy for prevention of posttraumatic seizures: a randomized trial. J Neurosurg. 1999;91(4):593-600.

32. Chen S, Wu H, Klebe D, Hong Y, Zhang J. Valproic acid: a new candidate of therapeutic application for the acute central nervous system injuries. Neurochem Res. Epub 2014 Jan 31.

33. Shetty AK. Prospects of levetiracetam as a neuroprotective drug against status epilepticus, traumatic brain injury, and stroke. Front Neurol. 2013;4:172.

34. Wang H, Gao J, Lassiter TF, et al. Levetiracetam is neuroprotective in murine models of closed head injury and subarachnoid hemorrhage. Neurocrit Care. 2006;5(1):71-78.

35. Zou H, Brayer SW, Hurwitz M, Niyonkuru C, Fowler LE, Wagner AK Neuroprotective, neuroplastic, and neurobehavioral effects of daily treatment with levetiracetam in experimental traumatic brain injury. Neurorehabil Neural Repair. 2013;27(9):878-888.

36. Lee DS, Ryu HJ, Kim JE, et al. The effect of levetiracetam on status epilepticus-induced neuronal death in the rat hippocampus. Seizure. 2013;22(5):368-377.

37. Löscher W, Brandt C. Prevention or modification of epileptogenesis after brain insults: experimental approaches and translational research. Pharmacol Rev. 2010;62(4):668-700.
38. Margineanu DG, Matagne A, Kaminski RM, Klitgaard H. Effects of chronic treatment with levetiracetam on hippocampal field responses after pilocarpine-induced status epilepticus in rats. Brain Res Bull. 2008;77(5):282-285.

39. Russo E, Citraro R, Scicchitano F, et al. Comparison of the antiepileptogenic effects of an early long-term treatment with ethosuximide or levetiracetam in a genetic animal model of absence epilepsy. Epilepsia. 2010;51(8):1560-1569.

40. Yan HD, Ji-qun C, Ishihara K, Nagayama T, Serikawa T, Sasa M. Separation of antiepileptogenic and antiseizure effects of levetiracetam in the spontaneously epileptic rat (SER). Epilepsia. 2005;46(8): 1170-1177.

41. Aldenkamp A, Arends J. The relative influence of epileptic EEG discharges, short nonconvulsive seizures, and type of epilepsy on cognitive function. Epilepsia. 2004;45(1):54-63.

42. Nicolai J, Ebus S, Biemans DP, et al. The cognitive effects of interictal epileptiform EEG discharges and short nonconvulsive epileptic seizures. Epilepsia. 2012;53(6):1051-1059.

43. Aldenkamp A. Effects of epileptiform EEG discharges on cognitive function. In: Zeman A, Kapur N, Jones-Gotman M, editors. Epilepsy and Memory. Oxford: Oxford University Press; 2012:160-176.

44. Kossoff EH, Los JG, Boatman DF. A pilot study transitioning children onto levetiracetam monotherapy to improve language dysfunction associated with benign rolandic epilepsy. Epilepsy Behav. 2007;11(4):514-517.

45. Stodieck S, Steinhoff BJ, Kolmsee S, van Rijckevorsel K. Effect of levetiracetam in patients with epilepsy and interictal epileptiform discharges. Seizure. 2001;10(8):583-587.

46. Cho JR, Koo DL, Joo EY, et al. Effect of levetiracetam monotherapy on background EEG activity and cognition in drug-naïve epilepsy patients. Clin Neurophysiol. 2012;123(5):883-891.

47. Bushnik T, Englander J, Wright J, Kolakowsky-Hayner SA. Traumatic brain injury with and without late posttraumatic seizures: what are the impacts in the post-acute phase: a NIDRR Traumatic Brain Injury Model Systems study. J Head Trauma Rehabil. 2012;27(6):E36-E44.

48. Kolakowsky-Hayner SA, Wright J, Englander J, Duong T, LadleyO'Brien S. Impact of late post-traumatic seizures on physical health and functioning for individuals with brain injury within the community. Brain Inj. 2013;27(5):578-586.

49. Hamm RJ, Dixon CE, Gbadebo DM, et al. Cognitive deficits following traumatic brain injury produced by controlled cortical impact. J Neurotrauma. 1992;9(1):11-20.

50. Coulter DA, Rafiq A, Shumate M, Gong QZ, DeLorenzo RJ, Lyeth BG. Brain injury-induced enhanced limbic epileptogenesis: anatomical and physiological parallels to an animal model of temporal lobe epilepsy. Epilepsy Res. 1996;26(1):81-91.

51. Niskanen JP, Airaksinen AM, Sierra A, et al. Monitoring functional impairment and recovery after traumatic brain injury in rats by FMRI. J Neurotrauma. 2013;30(7):546-556.

52. Pitkänen A, Immonen RJ, Gröhn OH, Kharatishvili I. From traumatic brain injury to posttraumatic epilepsy: what animal models tell us about the process and treatment options. Epilepsia. 2009;50 Suppl 2: 21-29.

53. Hoover RC, Motta M, Davis J, et al. Differential effects of the anticonvulsant topiramate on neurobehavioral and histological outcomes following traumatic brain injury in rats. $J$ Neurotrauma. 2004;21(5):501-512.

54. Vespa PM, McArthur DL, Xu Y, et al. Nonconvulsive seizures after traumatic brain injury are associated with hippocampal atrophy. Neurology. 2010;75(9):792-798.

55. Timofeev I, Carpenter KL, Nortje J, et al. Cerebral extracellular chemistry and outcome following traumatic brain injury: a microdialysis study of 223 patients. Brain. 2011;134(Pt 2):484-494.

56. Vespa PM, Miller C, McArthur D, et al. Nonconvulsive electrographic seizures after traumatic brain injury result in a delayed, prolonged increase in intracranial pressure and metabolic crisis. Crit Care Med. 2007;35(12):2830-2836. 
57. Mani R, Schmitt SE, Mazer M, Putt ME, Gaieski DF. The frequency and timing of epileptiform activity on continuous electroencephalogram in comatose post-cardiac arrest syndrome patients treated with therapeutic hypothermia. Resuscitation. 2012;83(7):840-847.

58. Szaflarski JP, Rackley AY, Kleindorfer DO, et al. Incidence of seizures in the acute phase of stroke: a population-based study. Epilepsia. 2008;49(6):974-981.

59. Vespa PM, Nenov V, Nuwer MR. Continuous EEG monitoring in the intensive care unit: early findings and clinical efficacy. J Clin Neurophysiol. 1999;16(1):1-13.

60. Vespa PM, Nuwer MR, Nenov V, et al. Increased incidence and impact of nonconvulsive and convulsive seizures after traumatic brain injury as detected by continuous electroencephalographic monitoring. $J \mathrm{Neu}$ rosurg. 1999;91(5):750-760.

61. Loring DW, Williamson DJ, Meador KJ, Wiegand F, Hulihan J. Topiramate dose effects on cognition: a randomized double-blind study. Neurology. 2011;76(2):131-137.

62. Martin R, Kuzniecky R, Ho S, et al. Cognitive effects of topiramate, gabapentin, and lamotrigine in healthy young adults. Neurology. 1999;52(2):321-327.

63. Meador KJ, Loring DW, Vahle VJ, et al. Cognitive and behavioral effects of lamotrigine and topiramate in healthy volunteers. Neurology. 2005;64(12):2108-2114.

64. Salinsky MC, Storzbach D, Spencer DC, Oken BS, Landry T, Dodrill CB. Effects of topiramate and gabapentin on cognitive abilities in healthy volunteers. Neurology. 2005;64(5):792-798.

65. Blum D, Meador K, Biton V, et al. Cognitive effects of lamotrigine compared with topiramate in patients with epilepsy. Neurology. 2006;67(3):400-406.

66. Lee S, Sziklas V, Andermann F, et al. The effects of adjunctive topiramate on cognitive function in patients with epilepsy. Epilepsia. 2003;44(3):339-347.

67. Mula M, Trimble MR, Thompson P, Sander JW. Topiramate and word-finding difficulties in patients with epilepsy. Neurology. 2003;60(7):1104-1107.

68. Szaflarski JP, Allendorfer JB. Topiramate and its effect on fMRI of language in patients with right or left temporal lobe epilepsy. Epilepsy Behav. 2012;24(1):74-80.

69. Dikmen SS, Temkin NR, Miller B, Machamer J, Winn HR. Neurobehavioral effects of phenytoin prophylaxis of posttraumatic seizures. JAMA. 1991;265(10):1271-1277.

70. Gallassi R, Morreale A, Lorusso S, Procaccianti G, Lugaresi E, Baruzzi A. Carbamazepine and phenytoin. Comparison of cognitive effects in epileptic patients during monotherapy and withdrawal. Arch Neurol. 1988;45(8):892-894.

71. Gomer B, Wagner K, Frings L, et al. The influence of antiepileptic drugs on cognition: a comparison of levetiracetam with topiramate. Epilepsy Behav. 2007;10(3):486-494.

72. Helmstaedter C, Witt JA. The effects of levetiracetam on cognition: a non-interventional surveillance study. Epilepsy Behav. 2008;13(4):642-649.

73. Naidech AM, Kreiter KT, Janjua N, et al. Phenytoin exposure is associated with functional and cognitive disability after subarachnoid hemorrhage. Stroke. 2005;36(3):583-587.

74. Trimble MR. Cognitive hazards of seizure disorders. Epilepsia. 1988;29 Suppl 1:S19-S24.

75. Andrewes DG, Bullen JG, Tomlinson L, Elwes RD, Reynolds EH. A comparative study of the cognitive effects of phenytoin and carbamazepine in new referrals with epilepsy. Epilepsia. 1986;27(2):128-134.

76. Gillham RA, Williams N, Wiedmann KD, Butler E, Larkin JG, Brodie MJ. Cognitive function in adult epileptic patients established on anticonvulsant monotherapy. Epilepsy Res. 1990;7(3):219-225.

77. Pulliainen V, Jokelainen M. Comparing the cognitive effects of phenytoin and carbamazepine in long-term monotherapy: a two-year follow-up. Epilepsia. 1995;36(12):1195-1202.
78. Aldenkamp AP, Alpherts WC, Diepman L, van 't Slot B, Overweg J, Vermeulen J. Cognitive side-effects of phenytoin compared with carbamazepine in patients with localization-related epilepsy. Epilepsy Res. 1994;19(1):37-43.

79. Duncan JS, Shorvon SD, Trimble MR. Effects of removal of phenytoin, carbamazepine, and valproate on cognitive function. Epilepsia. 1990;31(5):584-591.

80. Giurgea C. The "nootropic" approach to the pharmacology of the integrative activity of the brain. Cond Reflex. 1973;8(2):108-115.

81. Giurgea CE, Greindl MG, Preat S. Nootropic drugs and aging. Acta Psychiatr Belg. 1983;83(4):349-358.

82. Ciesielski AS, Samson S, Steinhoff BJ. Neuropsychological and psychiatric impact of add-on titration of pregabalin versus levetiracetam: a comparative short-term study. Epilepsy Behav. 2006;9(3): 424-431.

83. López-Góngora M, Martínez-Domeño A, Garcia C, Escartín A. Effect of levetiracetam on cognitive functions and quality of life: a one-year follow-up study. Epileptic Disord. 2008;10(4):297-305.

84. Helmstaedter C, Fritz NE, Kockelmann E, Kosanetzky N, Elger CE. Positive and negative psychotropic effects of levetiracetam. Epilepsy Behav. 2008;13(3):535-541.

85. Eddy CM, Rickards HE, Cavanna AE. The cognitive impact of antiepileptic drugs. Ther Adv Neurol Disord. 2011;4(6):385-407.

86. Neyens LG, Alpherts WC, Aldenkamp AP. Cognitive effects of a new pyrrolidine derivative (levetiracetam) in patients with epilepsy. Prog Neuropsychopharmacol Biol Psychiatry. 1995;19(3):411-419.

87. Huang CW, Pai MC, Tsai JJ. Comparative cognitive effects of levetiracetam and topiramate in intractable epilepsy. Psychiatry Clin Neurosci. 2008;62(5):548-553.

88. de Groot M, Douw L, Sizoo EM, et al. Levetiracetam improves verbal memory in high-grade glioma patients. Neuro-oncology. 2013;15(2):216-223.

89. Sanchez PE, Zhu L, Verret L, et al. Levetiracetam suppresses neuronal network dysfunction and reverses synaptic and cognitive deficits in an Alzheimer's disease model. Proc Natl Acad Sci U S A. 2012;109(42):E2895-E2903.

90. Meador KJ, Loring DW, Abney OL, et al. Effects of carbamazepine and phenytoin on EEG and memory in healthy adults. Epilepsia. 1993;34(1):153-157.

91. Osorio I, Burnstine TH, Remler B, Manon-Espaillat R, Reed RC. Phenytoin-induced seizures: a paradoxical effect at toxic concentrations in epileptic patients. Epilepsia. 1989;30(2):230-234.

92. Fountain N. Should levetiracetam replace phenytoin for seizure prophylaxis after neurosurgery? Epilepsy Curr. 2009;9(3):71-72.

93. Milligan TA, Hurwitz S, Bromfield EB. Efficacy and tolerability of levetiracetam versus phenytoin after supratentorial neurosurgery. Neurology. 2008;71(9):665-669.

94. Szaflarski JP, Meckler JM, Szaflarski M, Shutter LA, Privitera MD, Yates SL. Levetiracetam use in critically ill patients. Neurocrit Care. 2007;7(2):140-147.

95. Kilpatrick CJ, Davis SM, Hopper JL, Rossiter SC. Early seizures after acute stroke. Risk of late seizures. Arch Neurol. 1992; 49(5):509-511.

96. So EL, Annegers JF, Hauser WA, O’Brien PC, Whisnant JP. Population-based study of seizure disorders after cerebral infarction. Neurology. 1996;46(2):350-355.

97. Klitgaard H, Pitkänen A. Antiepileptogenesis, neuroprotection, and disease modification in the treatment of epilepsy: focus on levetiracetam. Epileptic Disord. 2003;5 Suppl 1:S9-S16.

98. Pitkänen A, Bolkvadze T, Immonen R. Anti-epileptogenesis in rodent post-traumatic epilepsy models. Neurosci Lett. 2011;497(3): 163-171.

99. Dichter MA. Emerging concepts in the pathogenesis of epilepsy and epileptogenesis. Arch Neurol. 2009;66(4):443-447.

100. Herman ST. Clinical trials for prevention of epileptogenesis. Epilepsy Res. 2006;68(1):35-38. 
101. Mani R, Pollard J, Dichter MA. Human clinical trails in antiepileptogenesis. Neurosci Lett. 2011;497(3):251-256.

102. Specht U, May T, Schulz R, et al. Cerebellar atrophy and prognosis after temporal lobe resection. $J$ Neurol Neurosurg Psychiatry. 1997;62(5):501-506.

103. Inaba K, Menaker J, Branco BC, et al. A prospective multicenter comparison of levetiracetam versus phenytoin for early posttraumatic seizure prophylaxis. J Trauma Acute Care Surg. 2013;74(3):766-773.

104. Kilbride RD, Costello DJ, Chiappa KH. How seizure detection by continuous electroencephalographic monitoring affects the prescribing of antiepileptic medications. Arch Neurol. 2009;66(6):723-728.

105. DeLorenzo RJ, Waterhouse EJ, Towne AR, et al. Persistent nonconvulsive status epilepticus after the control of convulsive status epilepticus. Epilepsia. 1998;39(8):833-840.

106. Privitera M, Hoffman M, Moore JL, Jester D. EEG detection of nontonic-clonic status epilepticus in patients with altered consciousness. Epilepsy Res. 1994;18(2):155-166.

107. Varelas PN, Mirski MA. Management of seizures in critically ill patients. Curr Neurol Neurosci Rep. 2004;4(6):489-496.

108. Vespa PM, Boscardin WJ, Hovda DA, et al. Early and persistent impaired percent alpha variability on continuous electroencephalography monitoring as predictive of poor outcome after traumatic brain injury. J Neurosurg. 2002;97(1):84-92.
109. Lee CY, Fu WM, Chen CC, Su MJ, Liou HH. Lamotrigine inhibits postsynaptic AMPA receptor and glutamate release in the dentate gyrus. Epilepsia. 2008;49(5):888-897.

110. Rogawski MA. Revisiting AMPA receptors as an antiepileptic drug target. Epilepsy Curr. 2011;11(2):56-63.

111. Russo E, Constanti A, Ferreri G, Citraro R, De Sarro G. Nifedipine affects the anticonvulsant activity of topiramate in various animal models of epilepsy. Neuropharmacology. 2004;46(6):865-878.

112. Russo E, Gitto R, Citraro R, Chimirri A, De Sarro G. New AMPA antagonists in epilepsy. Expert Opin Investig Drugs. 2012; 21(9):1371-1389.

113. Liu Y, Barks JD, Xu G, Silverstein FS. Topiramate extends the therapeutic window for hypothermia-mediated neuroprotection after stroke in neonatal rats. Stroke. 2004;35(6):1460-1465.

114. Brandt C, Heile A, Potschka H, Stoehr T, Löscher W. Effects of the novel antiepileptic drug lacosamide on the development of amygdala kindling in rats. Epilepsia. 2006;47(11):1803-1809.

115. Gaspard N, Foreman B, Judd LM, et al. Intravenous ketamine for the treatment of refractory status epilepticus: a retrospective multicenter study. Epilepsia. 2013;54(8):1498-1503.
Neuropsychiatric Disease and Treatment

\section{Publish your work in this journal}

Neuropsychiatric Disease and Treatment is an international, peerreviewed journal of clinical therapeutics and pharmacology focusing on concise rapid reporting of clinical or pre-clinical studies on a range of neuropsychiatric and neurological disorders. This journal is indexed on PubMed Central, the 'PsycINFO' database and CAS,

\section{Dovepress}

and is the official journal of The International Neuropsychiatric Association (INA). The manuscript management system is completely online and includes a very quick and fair peer-review system, which is all easy to use. Visit http://www.dovepress.com/testimonials.php to read real quotes from published authors. 